\title{
TÉCNICA DE “CONTINOUS RESISTIVITY PROFILE (CRP) PARA O MAPEAMENTO DOS RECIFES SUBMERSOS COSTEIROS DE PORTO SEGURO - BA
}

\author{
AUTOR: MATEUS ALEXANDER CAMPECHE GAMA \\ CO-AUTOR/ORIENTADOR: ANDRESA OLIVA
}

Resumo: Considerando que os recifes de corais fornecem importantes serviços às populações costeiras, como proteção a eventos erosivos, atividades culturais, regulação do clima e alimentação torna-se necessário o reconhecimento dos ambientes quanto a sua estrutura e características morfológicas. O presente trabalho tem o tem por intuito utilizar a técnicas geofísicas para mapear e delimitar recifes submersos costeiros da região de Porto Seguro. Realizou-se aquisições batimétricas com um sonar monofeixe, em seis recifes costeiros da região: Recife Itassepanema, recife Pedra Corvina, recife Tabaxoara, recife Itassemirim, recife Itassepocu e recife Sororoca. Após a aquisição dos dados foi realizada a correção de maré e análises de geoestatística (histograma, scatter plot, coeficiente de correlação, mapa variográfico e variograma) para gerar a interpolação melhor ajustada dos recifes. As análises de geoestatística foram através do software ISATIS-Neo e a interpolação através do software Quantum-GIS (QGIS) utilizado o método da Krigagem, posteriormente sendo realizado validação cruzada com o método Vizinho Natural. Após as análises, observou-se que as características morfológicas diferenciaram entre os recifes, a partir da sua distância da costa e do rio Buranhém. As interpolações são fidedignas às imagens observadas via satélite demonstrando que a aquisição de dados de baixo custo utilizando o single beam sonar, sendo eficaz na delimitação estrutural dos recifes costeiros e possibilitar futuras pesquisas na zona de estudo.

Palavras-chave: Mapeamento recifal, sonar monofeixe, interpolação, Porto Seguro. 